\section{Industry struggles on despite opposition}

\section{Washington}

WiLL nuclear power play a role in the future energy plans of the United States? The Nuclear Power Oversight Committee, a nuclear power industry body, issued a white paper (policy document) last week calling for an easing of government regulations so to encourage the building of new nuclear plants. But industry analysts say nuclear power is dying in the United States, not because of regulation but because the industry has lost economic and political viability.

James O'Connor, chairman of the committee, says that growth in demand for electricity in recent years has far exceeded even the power industry's projections and that the United States is now running "perilously close to capacity margins that leave very little room for error". He points to the emergency measures, such as voltage reduction, that many utility companies had to take during last summer's heat wave as a sign of the serious supply difficulties that lie ahead.

If demand for electricity in the United States continues to grow at $2-3$ per cent a year, 120-220 large new nuclear power plants will have to be built by the turn of the century. The white paper argues that new plants could offer the most cost-effective new source if the government were to ease regulatory controls by, for example, introducing a single-licence system instead of, as now, requiring utility companies to obtain both a construction and an operating licence for new plants.

But Christopher Flavin, vice-president for research at the Worldwatch Institute, who has been monitoring the nuclear industry for the past decade, says the industry's figures for the cost of nuclear power are based on existing plants both old and new. Since the Three Mile Island accident, increased safety requirements have quadrupled plant construction costs and nuclear power is now more than "twice as expensive as competing sources". But O'Connor argues that the biggest additional cost in building new plants is delay due to complex regulatory controls.

Concern about global climate change has prompted Congress to reassess the pros and cons of nuclear power, an energy source free from carbon dioxide emissions, as the industry is ready to point out. But Flavin says that, if the new legislation introduced by Congress to deal with global warming is accepted, there will be a "stampede" towards the development of renewable energy sources, not nuclear power.

Public opposition to nuclear power in the United States remains widespread. Legislators introducing global warming bills have attentuated or omitted references to nuclear power to gain wider acceptance.

David Swinbanks

Legacy of Three Mile Island

\section{Boston}

A DECADE after the partial meltdown of the Three Mile Island (TMI) Unit 2 reactor near Harrisburg, Pennsylvania, on 28 March 1979, cleaning up continues at a cost of $\$ 1,000$ million - nearly $\$ 300$ million more than the cost of building the reactor in the first place. But the implications of the accident for the commercial nuclear industry are almost certainly far greater.

So far, workers have removed most of the damaged nuclear fuel from the Unit 2 reactor vessel. This has been accomplished by a team of more than 1,000 people, including a group operating specially designed equipment from a rotating platform above the reactor vessel. Working almost continuously since October 1985 , the clean-up team has removed radioactive debris ranging in size from gravellike material to a fused hard crust, up to 5 feet thick, formed from the molten fuel rods during the accident.

If all goes according to plan, the 'defuelling' process should be complete by the end of 1990 , when Unit 2 will be shut and monitored for approximately 30 years, until the end of the planned lifespan of the operating Unit 1 reactor nearby. A full decommissioning and dismantling of Unit 2 will be postponed until the job can be undertaken for both reactor units together, according to Doug Bedell, spokesman for GPU Nuclear, TMI's owner.

Bedell emphasizes that enough material has been removed to dispel any chance of "a critical event", but he acknowledges that, because residual caesium has permeated the basement walls, "unacceptable" and potentially dangerous levels of radiation will still be left in the basement area of the Unit 2 reactor until decommissioning begins next century.

Since the clean-up began, 150 tons of highly radioactive debris has been hauled away from the reactor. But because there is not yet a functioning repository for highlevel commercial nuclear waste anywhere in the United States, the debris from TMI continues to be stored "temporarily" at the National Engineering Laboratory in Idaho where researchers have studied the material to reconstruct the precise course of the accident. A plan to evaporate the remaining 2 million gallons of radioactive water at the TMI site still awaits approval from the Nuclear Regulatory Commission.

The accident at TMI Unit 2 began after only 11 months of operation when a pump providing feedwater to the reactor core clogged during full power operation. After the plant shut down automatically, a relief valve opened to diminish the builtup pressure and temperature in the reactor, letting out steam and water.

Undetected by the operators, this valve remained open for 2 hours, allowing the escape of nearly a million gallons of the coolant water covering the reactor fuel. As approximately half of the reactor core became uncovered, the radioactive water overflowed designed catchments, collecting in the basements of the reactor and auxiliary buildings. Without the coolant water, temperatures in the pressurized-water reactor rose quickly, causing some of the uranium fuel to melt.

The accident at TMI prompted a widespread response in the nuclear industry. Within weeks of the disaster, the Electric Power Research Institute (supported by the utilities) established an organization called the Nuclear Safety Analysis Center (NSAC) to analyse the accident and to inform other utilities of any future malfunctions or other information that could be useful.

Later that year, the industry also formed the safety-oriented group called the Institute of Nuclear Power Operations (INPO). Among its other functions, INPO runs a computer network linking nuclear power plant operators with experts at INPO and NSAC to provide instantaneous advice and information. According to William Layman, since the accident at TMI, the industry has learned that "the price of safety is eternal vigilance".

But although the industry can point to strengthened safety procedure in the aftermath of the TMI accident, most agree that the incident's greatest legacy is a sustained level of lingering public fear and opposition to nuclear power in the United States.

More than 2,000 lawsuits claiming health and psychological damage from the TMI accident are still pending, despite measurements after the accident that showed that the highest possible wholebody dose to any one individual was less than 100 millirem, or only slightly greater than the average most people are exposed to from medical and dental radiation in a year.

Most observers agree that the TMI accident was a clear turning-point for the US nuclear industry, although poor performance, steeply rising construction costs and slowly growing demand for electricity may earlier have presaged the industry's decline. Although performance has improved and dependence on nuclear power as a fraction of energy supply in the United States has since grown, no plants have been ordered since the accident and all of the 47 units ordered in the United States since 1974 have been cancelled.

Seth Shuiman 